\title{
AS PRÁTICAS SEXUAIS E O CUIDADO COM A SAÚDE PELOS OLHARES DE ADOLESCENTES CABO-VERDIANOS E BRASILEIROS
}

\author{
SEXUAL PRACTICES AND HEALTH CARE BY THE PERCEPTION \\ OF CAPE VERDIAN AND BRAZILIAN ADOLESCENTS
}

LAS PRÁCTICAS SEXUALES Y EL CUIDADO CON LA SALUD DESDE LA MIRADA
DE ADOLESCENTES CABO-VERDIANOS Y BRASILEÑOS

Julio Cesar Bresolin Marinho1; João Alberto da Silva ${ }^{2}$

\section{RESUMO}

A saúde do adolescente tem sido pauta de discussões visto que esses sujeitos configuram-se como vulneráveis. Neste trabalho tratamos da temática das práticas sexuais e procuramos analisar as percepções morais e éticas de adolescentes sobre a questão. A pesquisa é qualitativa e configurou-se como explicativa. Foram realizados cinco grupos focais tendo como instrumentos de coleta de dados os dilemas morais. Participaram 45 adolescentes de Cabo-Verde e Brasil. Observamos que os adolescentes tinham conhecimento sobre os comportamentos saudáveis no que tange às práticas sexuais. No entanto, isso não se configurou como garantia de que esse domínio da informação fosse suficiente para balizar a conduta do sujeito, pois não podemos pensar a racionalidade e a afetividade de forma seccionada. Pode-se saber o que fazer e querer, mas a intensidade desta vontade (força de vontade) é fundamental e vinculada à afetividade.

PALAVRAS-CHAVE: Educação em Saúde. Moral. Gravidez.

\begin{abstract}
Adolescent health has been the subject of discussions since these subjects are vulnerable. We deal with the sexual practices and try to analyze the moral and ethical perceptions of adolescents on the issue. The research is qualitative and configured as explanatory. Five focal groups were held using as data collection tools the moral dilemmas. Participants were 45 adolescents from Cape Verde and Brazil. We observed that adolescents were knowledgeable about healthy behaviors regarding sexual practices. However, this was not configured as a guarantee that this domain of information would be sufficient to guide the behavior of the subject because we can not think of rationality and affectivity in a sectioned way. One can know what to do and want, but the intensity of this will (willpower) is fundamental and linked to affectivity.
\end{abstract}

KEYWORDS: Health Education. Moral. Pregnancy.

\footnotetext{
${ }^{1}$ Doutor em Educação em Ciências - Associação Ampla entre UFRGS/UFSM/FURG, com período sanduíche na Universidade de Cabo Verde - UniCV (Praia, Ilha de Santiago, Cabo Verde). Professor Adjunto - Universidade Federal do Pampa - UNIPAMPA, Campus São Gabriel e Professor Colaborador - Universidade Federal de Santa Maria (UFSM) E-mail: marinhojcb@gmail.com

${ }^{2}$ Doutorado em Educação - Universidade Federal do Rio Grande do Sul. Doutorado-sanduíche na Universidade de Genebra. Professor Associado na Universidade Federal do Rio Grande-FURG. E-mail: joaosilva@furg.com.br Submetido em: 15/09/2019 - Aceito em: 30/06/2020
}

(C) ETD-Educação Temática Digital Campinas, SP $\quad$ v.23 n.1 $\quad$ p. 135-156 jan./mar.2021




\section{RESUMEN}

La salud del adolescente ha sido pauta de discusiones ya que esos sujetos se configuran como vulnerables. En este trabajo tratamos de la temática de las prácticas sexuales y buscamos analizar las percepciones morales y éticas de adolescentes sobre la cuestión. La investigación es cualitativa y configurada como explicativa. Se realizaron cinco grupos focales teniendo como instrumentos de recolección de datos los dilemas morales. Participaron 45 adolescentes de Cabo Verde y Brasil. Observamos que los adolescentes tenían conocimiento sobre los comportamientos sanos en lo que se refiere a las prácticas sexuales. Sin embargo, esto no se configuró como garantía de que ese dominio de la información fuera suficiente para balizar la conducta del sujeto, pues no podemos pensar la racionalidad y la afectividad de forma seccionada. Se puede saber qué hacer y querer, pero la intensidad de esta voluntad (fuerza de voluntad) es fundamental y vinculada a la afectividad.

PALAVRAS-CLAVE: Educación en Salud. Moral. Embarazo.

\section{INTRODUÇÃO}

A adolescência é o período da vida que se caracteriza por uma série de transições, sendo a passagem à sexualidade com um/a parceiro/a a de maior repercussão (BRÊTAS, MORENO, EUGENIO, SALA, VIEIRA e BRUNO, 2008; BRÊTAS, OHARA, JARDIM e MUROYA, 2009; SILVA, DIAS, MAIA, PEREIRA, VIEIRA, e PINHEIRO, 2010). É muito usual o início das práticas sexuais na adolescência acontecerem sem proteção. Romero, Medeiros, Vitalle e Wehba (2007, p. 17) apontam como algumas dessas razões

a desinformação, na medida em que os adolescentes parecem desconhecer o seu período fértil ou o uso de anticoncepcionais do modo correto; ou simplesmente não acreditam na existência do risco de gravidez e doenças desde a primeira relação sexual, considerando-se indestrutíveis e inatingíveis em seu pensamento mágico.

A Pesquisa Nacional de Saúde do Escolar - PeNSE apresenta que 87,3\% dos escolares do 9o ano do Ensino Fundamental receberam informações, na escola, sobre infecções sexualmente transmissíveis (ISTs) e AIDS. Dado similar é obtido no que se refere ao recebimento de informações sobre prevenção de gravidez, visto que 79,2\% dos escolares responderam que já obtiveram tais informações nas instituições de ensino (BRASIL. IBGE, 2016). Esses indicadores nos levam a compreender que os adolescentes brasileiros estão recebendo informações nas escolas relacionadas à saúde sexual, no entanto, indicadores como os observados na Figura 1 nos possibilitam evidenciar um crescimento nos casos de infecção pelo HIV em adolescentes (nas faixas de 15 a 19 anos e de 20 a 24). 


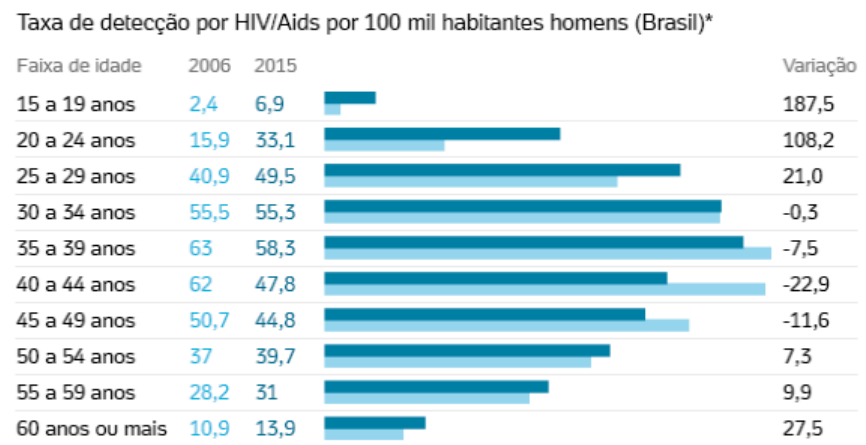

Figura 1 - Aumento nos casos de infecção pelo HIV em adolescentes

Fonte: Uol notícias ${ }^{3}$

Junto a esses indicadores, o relatório "Aceleração do progresso para a redução da gravidez na adolescência na América Latina e no Caribe" nos mostra que a taxa mundial de gravidez adolescente é estimada em 46 nascimentos para cada 1 mil meninas (de 15 a 19 anos), de modo que na América Latina e no Caribe a taxa é estimada em 65,5 nascimentos, sendo no Brasil de 68,44.

Em Cabo Verde, outro país investigado neste estudo, apesar de possuir uma taxa de prevalência do HIV/AIDS considerada baixa (0,8\%), a incidência dos casos de infecção pelo vírus tem aumentado. A taxa de deteç̧ão de 6,2 por cem mil habitantes em 1995 passou para 17 por cem mil em 2000 e atingiu 62,7 por cem mil em 2009. Os números em relação à gravidez também não são animadores, visto que dados do Ministério da Saúde cabo-verdiano apresentam um crescimento na taxa de gravidez na adolescência (15-17 anos) nos últimos anos passando de 11,4\% no ano 2000, para 12,5\% em 2005 e 15\% em 2009 (UNICEF, 2011).

Dessa forma, a questão que nos mobiliza gira em torno de: Por que mesmo com o recebimento de informações, obtidas na escola e outros espaços educativos ${ }^{5}$, os adolescentes não têm atitudes saudáveis no que se relaciona às práticas sexuais? Acreditamos que compreender tal questão configura-se como importante, principalmente para a elaboração de ações de Educação em Saúde a serem realizadas nas escolas, bem como em outros espaços educativos. É importante mencionarmos que o foco deste estudo são as práticas sexuais realizadas pelos adolescentes.

\footnotetext{
3 Disponível em: <https://noticias.uol.com.br/saude/ultimas-noticias/redacao/2017/08/15/o-que-explica-adisparada-de-infeccoes-por-hiv-entre-jovens-brasileiros.htm>. Acesso em: 09 jul. 2018.

${ }^{4}$ Informação disponível em: <https://nacoesunidas.org/taxa-de-gravidez-adolescente-no-brasil-esta-acima-damedia-latino-americana-e-caribenha/>. Acesso em: 09 jul. 2018.

${ }^{5}$ Entendemos que em relação as práticas sexuais, as informações estão disponíveis para além do espaço da escola, como por exemplo na mídia televisiva e nas campanhas do Ministério da Saúde.
}

(C) ETD-Educação Temática Digital Campinas, SP $\quad$ v.23 n.1 $\quad$ p. 135-156 jan./mar.2021


A abordagem compreensiva deste trabalho residiu no olhar da moralidade, pois concebemos que ela atua como reguladora das ações humanas, assim não nos é possível dissociar a questão moral e ética da saúde. D'Aurea-Tardeli (2008, p. 290) vai defender que "a motivação para a ação é sempre afetiva, e a dimensão dessa afetividade é o seu valor". Ao responder a indagação "Como devo agir?", em relação à saúde, o sujeito irá acabar por responder também o questionamento "Que vida quero viver?", de forma que o ímpeto do dever irá possibilitar a compreensão do valor que ele atribuí a sua vida, bem como o valor que atribuem a si próprio (expansão de si). Assim, nosso objetivo reside em analisar as percepções morais e éticas nos discursos de adolescentes cabo-verdianos e brasileiros no que tange às práticas sexuais.

\section{MORAL E ÉTICA}

Jean Piaget é pioneiro ao utilizar um enfoque construtivista para o estudo moral. Sua ideia, no que tange ao desenvolvimento moral, reside na passagem da heteronomia para autonomia. Caracteriza a primeira como resultado da coação moral, marcada pelo respeito unilateral que "é a origem da obrigação moral e do sentimento do dever: toda ordem, partindo de uma pessoa respeitada, é o ponto de partida de uma regra obrigatória" (PIAGET, 1994, p. 154). Quando as relações de coação dão lugar a relações cooperativas, "o respeito unilateral dá lugar ao respeito mútuo ou recíproco, graças ao qual se abre o caminho para a conquista da autonomia moral pelo sujeito" (FREITAS, 2002, p. 19). Piaget (1994, p. 155) considera que existe autonomia moral quando "a consciência considera como necessário um ideal, independente de qualquer pressão exterior".

No que tange às definições para os vocábulos moral e ética, constatamos que essas são diversas e possuem variação dependendo da aposta teórica adotada. Neste estudo, compreendemos moral e ética segundo La Taille (2006), o qual, em linhas gerais, estabelece que moral configura-se como um sistema de regras e princípios que corresponde à indagação a pergunta "Como devo agir?". Já a reflexão ética, procura responder "Que vida quero viver?", ocupando-se assim da questão da felicidade ou da vida boa. Para o autor, moral relaciona-se com deveres e ética com a busca de uma vida boa, uma vida que "vale a pena ser vivida".

Em relação ao plano moral, La Taille (2006, p. 53-54) concebe que age moral quem assim o quer, pois não se pode dissociar "dever" do "querer" e nos ilustra da seguinte forma:

\footnotetext{
Se legitimo a regra que diz ser um dever ajudar as pessoas necessitadas, abdico da liberdade de ir passear tranquilamente no bosque, se alguém precisar de minha ajuda. E isso vale para todas as regras morais: ao dizerem o que se deve fazer, elas limitam o campo das ações possíveis, portanto, limitam a liberdade. Porém, como já vimos, somente age moralmente quem se sente intimamente obrigado a tal, e não quem é coagido por algum poder exterior. Logo, o sujeito moral é, por definição, livre, porque é ele mesmo quem decide agir por dever.
} 
A exemplificação apresentada nos possibilita compreender por que "somente é moral quem assim o quer", visto que considera o sujeito moral livre, pois é o próprio sujeito que optou por agir guiado pelo dever e, ao realizar essa escolha acaba tendo limitações no campo das ações possíveis. Ao relacionarmos tal constatação ao campo da Educação em Saúde, podemos inferir que um adolescente que zele pela sua saúde, tendo uma vida saudável, possui grande apreço por ela, atribuindo um valor muito significativo a si de forma que procura se preservar na tentativa de ter uma vida boa. Para que o sujeito consiga se atribuir valor significativo é necessária a construção das representações de si com valor positivo (LA TAILLE, 2009), para que assim seja possível o desenvolvimento da autoestima, da autoconfiança e do autorrespeito.

No que tange ao plano ético, La Taille (2006) acredita que viver uma vida que faça sentido reside em condição necessária para a "vida boa", seja ela qual for e, assim, acabamos por encontrar um elemento essencial à definição do plano ético. $O$ autor consegue ir além e postula que ao escolher um sentido para a vida e formas de viver, o sujeito acaba se definindo como ser. Dessa forma, acredita que a resposta para o "como viver?" deve permitir a realização da expansão de si próprio. Ele compreende a expressão "expansão" como uma busca de novos horizontes de ação, uma busca da superação de si próprio, para conseguir enxergar a si próprio como uma pessoa de valor. Acaba assim, por visualizar que ver a si próprio como pessoa de valor é condição necessária para o gozo da felicidade, da "vida boa".

Para compreender os comportamentos morais dos indivíduos, La Taille (2006, p. 51) acredita que precisamos conhecer a perspectiva ética que adotam e afirma que

somente sente-se obrigado a seguir determinados deveres quem os concebe como expressão de valor do próprio eu, como tradução de sua auto-afirmação. Em suma, identificamos na 'expansão de si próprio' e no valor decorrente atribuído ao eu a fonte energética das ações significativas em geral, e das ações morais em particular. Em poucas palavras, identificamos no plano ético as motivações que explicam as ações no plano moral.

Assim, o sentimento de obrigatoriedade moral depende da expressão do valor do próprio eu. Evidencia-se que o sentimento de autorrespeito acaba unindo os planos moral e ético, considerando que o sujeito que respeita a moral, respeita a si próprio. Entendemos que o adolescente que se percebe como sujeito de valor irá cuidar de sua saúde, procurando se afastar das condutas de risco. Porém, se esse adolescente não se percebe como um sujeito de valor, pode acabar por não ter um cuidado mais acurado com sua saúde, pois não visualiza importância no zelo para consigo. 


\section{PROCEDIMENTOS METODOLÓGICOS}

A pesquisa, de abordagem qualitativa, configurou-se como explicativa e contou com a participação de 45 adolescentes ${ }^{6}$ imersos em contextos geográficos distintos: adolescentes africanos da Cidade da Praia (Ilha de Santiago, Cabo Verde) que estavam cursando o ensino secundário e adolescentes brasileiros que estavam cursando o Ensino Médio regular.

Para a produção de dados utilizamos a técnica do grupo focal, a qual possibilita compreender informações de naturezas diferentes, envolvendo conceitos e preconceitos, opiniões e ideias, valores, sentimentos e ações dos participantes a respeito de determinado assunto (GATTI, 2005). A possibilidade de trazer à tona o pensamento dos adolescentes através da abertura proporcionada a eles, em um grupo de pares, faz a técnica de grupo focal ser pertinente à investigação.

Foram realizados 5 grupos focais (Quadro 1) e o processo de recrutamento foi realizado pelas escolas ${ }^{7}$ em que os adolescentes estudavam, as quais foram contatadas previamente pelos pesquisadores. Os grupos foram todos realizados no ano de 2015, em salas das próprias instituições frequentadas pelos adolescentes, em período previamente agendado. No início de cada grupo focal os adolescentes foram dispostos em círculo para facilitar o contato visual de todos. Após, foi realizada a apresentação do pesquisador e dos adolescentes, bem como apresentada a dinâmica da discussão.

\footnotetext{
${ }^{6}$ Para o desenvolvimento da investigação os pesquisadores tiveram o aval de todas as escolas envolvidas e os adolescentes que aceitaram participar dos grupos focais receberam um Termo de Consentimento Livre e Esclarecido (TCLE) para que seus responsáveis assinassem, consentindo sua participação. O TCLE apresentava: informações sobre a pesquisa (título e informações do pesquisador responsável); a justificativa, os objetivos e procedimentos do estudo; a declaração do/a participante (se maior de 18 anos) ou do/a responsável pelo/a participante (se menor de 18 anos). No TCLE o/a participante ou o/a responsável pelo/a participante concordava com a participação no estudo e dava ciência que havia sido informado pelo pesquisador dos objetivos da pesquisa de maneira clara e detalhada, teve suas dúvidas esclarecidas e recebeu uma cópia do TCLE. Também era garantido que poderia retirar seu consentimento a qualquer momento, sem que isso levasse a qualquer penalidade. Foram disponibilizados termos para serem entregues a 12 alunos de cada escola contatada (totalizando $60 \mathrm{TCLE}$ ), os quais foram encaminhados pela equipe diretiva de cada uma das escolas para os alunos por elas selecionados. Recebemos a devolutiva de 45 TCLE, sendo que foi esse o número de participantes da investigação. Quem consentiu a participação dos menores de 18 anos nos grupos focais foi, em maior parte, a mãe dos adolescentes, seguido do pai e em alguns casos outro responsável. $O$ artigo é decorrente de uma tese de doutoramento e todos os dados foram coletados no ano de 2015. Nessa época, o Programa de Pós-Graduação em que a tese estava sendo produzida, não solicitava que os projetos passassem pela avaliação do Comitê de Ética em Pesquisa (CEP) da Universidade. A pesquisa foi financiada pela Coordenação de Aprimoramento de Pessoal de Nível Superior (CAPES) processo no 3283/15-1.

${ }^{7}$ As escolas foram contatadas e, em um primeiro momento, o projeto foi apresentado à direção para saber se as mesmas autorizavam a realização do estudo. Após a autorização, solicitamos que as escolas selecionassem de 10 a 12 adolescentes de ambos os gêneros, na faixa etária de 14 a 18 anos para integrar os grupos. Em Cabo Verde foram contatadas 3 escolas que aceitaram participar. Elas eram localizadas em três diferentes localidades da cidade da Praia. Já no Brasil, foi contatada uma escola que aceitou participar da investigação, tal escola é da rede Estadual de Ensino do Rio Grande do Sul (RS) e situa-se em um bairro da periferia. Salientamos que só participaram dos grupos focais os adolescentes que os responsáveis tivessem assinado o TCLE.
}

(C) ETD- Educação Temática Digital

Campinas, SP

v.23

n.1 p. $135-156$

jan. /mar.2021 
QUADRO 1. Organização e características dos grupos de adolescentes

\begin{tabular}{|c|c|c|}
\hline Contexto & Idade & Número de participantes \\
\hline \multirow{2}{*}{ Cabo Verde } & $14-15$ anos & 10 (3 gênero masculino e 7 gênero feminino) \\
\cline { 2 - 3 } & $16-17$ anos & 10 (5 gênero masculino e 5 gênero feminino) \\
\cline { 2 - 3 } & $14-17$ anos & 10 (4 gênero masculino e 6 gênero feminino) \\
\hline \multirow{2}{*}{ Brasil } & $16-18$ anos & 7 (2 gênero masculino e 5 gênero feminino) \\
\cline { 2 - 3 } & $14-17$ anos & 8 (2 gênero masculino e 6 gênero feminino) \\
\hline
\end{tabular}

Fonte: Os autores.

A aposta para mobilizar os grupos e fomentar uma discussão mais aprofundada das questões referentes às práticas sexuais residiu na utilização de um dilema moral. Acreditamos que a opção pelos grupos focais como técnica para produção de dados e o dilema como instrumento possibilitaram a obtenção de opiniões mais espontâneas e verdadeiras, fugindo de discursos programados que, muitas vezes, obtemos em pesquisas que utilizam entrevistas estruturadas.

Os dilemas morais, em linhas gerais "se constituem em narrativas breves de situações envolvendo conflitos de natureza moral que encerram valores diferentes" (GONÇALVES, 2015, p. 96). Kawashima, Martins e Bataglia (2015, p. 220) apontam que os dilemas apresentam situações que "não oferecem uma única solução, obrigando o sujeito a refletir, argumentar e justificar racionalmente a alternativa que lhe parece mais justa".

Para elaborar os dilemas levamos em conta as orientações de Puig (1988): definir com clareza o âmbito do dilema; definir um protagonista; propor uma escolha; propor temáticas morais; perguntar pelo que 'deveria fazer' o protagonista e 'por que' deveria fazer; formular outras perguntas e dilemas alternativos. Para discutir a temática das práticas sexuais com os adolescentes, elaboramos um dilema moral que foi desenvolvido duas vezes, de forma diferente. Em um primeiro momento o protagonista era um menino (Marcelo) e posteriormente foi substituído por uma menina (Carolina), como pode ser visto a seguir:

Marcelo/Carolina, um/a adolescente de 17 anos, conheceu um/a garota/o em uma festa e ambos sentiram-se interessados um pelo outro. Dançaram e ficaram juntos durante a festa. Quando a festa estava chegando ao seu final, Marcelo/Carolina convidou a/o menina/o que havia conhecido para ir à sua casa, pois seus pais estavam viajando e ele/a estava sozinho. A/O menina/o aceita o convite. Chegando lá conversaram mais um pouco e o clima foi esquentando, até que ambos resolveram transar. Marcelo/Carolina foi buscar o preservativo (camisinha), mas não encontrou e lembrou-se que não havia mais em sua casa. A/O menina/o que ele/a havia conhecido também não possuía. O que Marcelo/Carolina deve fazer? Por quê? 
Tal dilema se classifica como real, visto que seu conteúdo se refere a problemas que os sujeitos conhecem de perto ou já experimentaram de forma direta (PUIG, 1988). Optamos pela elaboração desse tipo de dilema, pois "se referem às suas próprias vidas. Tais exercícios são muito úteis porque asseguram ao máximo a implicação pessoal de quem os discute, mesmo que às vezes essa mesma implicação acarrete também sérias dificuldades e entraves emocionais" (PUIG, 1988, p. 59).

Quando os dilemas foram apresentados nos grupos focais, os adolescentes tiveram que se posicionar e explicar como agiriam se estivessem expostos a tal situação. Para apresentar os dilemas realizamos os seguintes procedimentos:

1ㅇ) realizamos a leitura oral da história com o grupo, bem como distribuímos o texto com o dilema por escrito;

20) questionamos se o dilema tinha ficado claro e se não tinham nenhuma dúvida relacionada a situação;

3) não existindo dúvidas, foi solicitado que os adolescentes realizassem a leitura do dilema para si mesmos e após solicitamos que explicassem o conflito pela ótica do protagonista.

Finalizado esse momento introdutório, partimos para a discussão do dilema moral propriamente dito, que sempre partiu da questão "o que o protagonista deveria fazer". Aqui os adolescentes puderam expressar suas opiniões acerca do dilema, bem como confrontar pontos de vista diversos sobre um mesmo problema moral (PUIG, 1988), por isso julgamos a utilização de dilemas como instrumento potencializador para o desenvolvimento dos grupos focais.

O registro das interações foi feito com auxílio de uma filmadora. Os dados registrados foram transcritos pelos pesquisadores e analisados mediante técnica de análise do Discurso do Sujeito Coletivo (DSC) (LEFEVRE; LEFEVRE, 2005; 2012), a qual como técnica:

\footnotetext{
consiste em uma série de operações sobre a matéria-prima dos depoimentos individuais ou de outro tipo de material verbal (artigos de jornais, revistas, discussões em grupo etc.), operações que redundam, ao final do processo, em depoimentos coletivos, ou seja, constructos confeccionados com estratos literais do conteúdo mais significativo dos diferentes depoimentos que apresentam sentidos semelhantes (LEFEVRE; LEFEVRE, 2012, p. 17).
}

Desse modo, a partir dos depoimentos dos adolescentes nos grupos, construímos os discursos coletivos resgatando todas as ideias que emergiram das discussões. Lefevre e Lefevre (2014) nos mostram que no DSC as opiniões de cada indivíduo, as quais apresentam sentidos semelhantes são reunidas em categorias semânticas gerais, como em qualquer

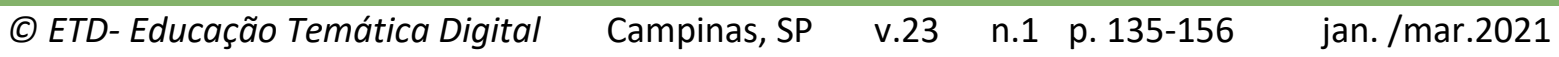


técnica de categorização. O diferencial dessa metodologia é que "a cada categoria estão associados os conteúdos das opiniões de sentido semelhante presentes em diferentes depoimentos, de modo a formar com tais conteúdos um depoimento síntese" (LEFEVRE; LEFEVRE, 2014, p. 503).

Para a construção dos discursos coletivos, o DSC utiliza quatro operadores: expressões-chave (ECH), Ideias centrais (IC), Ancoragem (AC) e Discurso do Sujeito Coletivo (DSC). As ECH consistem em pedaços, trechos, segmentos do discurso. São selecionadas pelo pesquisador e revelam a essência do conteúdo do discurso. As IC revelam e descrevem, da maneira mais sintética, precisa e fidedigna possível, os sentidos das ECH dos discursos analisados e de cada conjunto homogêneo de ECHs. As AC residem na expressão de uma dada teoria ou ideologia que o autor do discurso propala e que está embutida no seu discurso. 0 DSC é o discurso-síntese redigido na primeira pessoa do singular e composto pelas ECH que têm a mesma IC ou AC.

Para construir os DSC, primeiramente identificamos as ECH e nomeamos as IC/ACS presente no material que foi transcrito. Analisamos todas as IC/ACs agrupando por semelhanças em categorias e, por fim, construímos os discursos-sínteses (DSC), reconstruindo, com trechos de cada discurso singular, tantos discursos-síntese quantos se julgaram necessários para expressar uma representação social sobre o fenômeno (LEFEVRE; LEFEVRE, 2005). As IC e as AC que foram agrupadas por semelhanças na mesma categoria, foram aglutinadas e organizadas para construção do discurso na primeira pessoa do singular. Para dar maior fluidez ao discurso foram utilizados conectivos (assim, então, logo, enfim etc).

\section{RESULTADOS E DISCUSSÕES}

Como mencionamos na seção anterior, optamos por realizar o dilema moral em dois momentos, de duas formas diferentes. Primeiro realizamos com o protagonista sendo um menino - Marcelo, que posteriormente foi substituído por Carolina, uma menina. Tal escolha se deu, por termos como hipótese que, dependendo do gênero do protagonista, os pensamentos dos adolescentes poderiam ser diferentes. Ao construir os Discursos do Sujeito Coletivo, vimos que essa diferença não emergiu, pois sempre a escolha ficou sob responsabilidade da menina, até mesmo no dilema em que o protagonista era um rapaz.

Dessa forma, realizamos a fusão dos discursos, pois não existiam diferenças significativas em relação ao gênero. Ao unirmos os DSC ficamos com um total de quatro discursos, dois referentes a cada contexto. Apresentaremos inicialmente os discursos em que adolescentes, tanto cabo-verdianos quanto brasileiros, acreditam que não iria se concretizar a relação sexual (DSC 1CV e DSC 1BR) e, posteriormente, os que julgam que os adolescentes iriam ter a relação sexual mesmo desprotegidos (DSC 2CV e DSC 2BR). 


\subsection{Apresentação dos discursos e análises gerais}

Apresentamos inicialmente o DSC 1CV e o DSC 1BR, vejamos:

\section{DSC 1CV - Se fosse só a gravidez deixaria acontecer, mas tem doenças}

Eu não concordo com nenhum dos casos, nem o fato da menina querer ir pra casa do Marcelo e nem o fato dela pensar em fazer alguma coisa com ele. la transar com uma pessoa que mal conhece, que talvez nem o nome saiba, que não se sabe nem se a casa é do rapaz, se não é tudo mentira, e vai transar? Nem com camisinha, nem sem camisinha, ela não deveria nem ir pra casa do rapaz e a menina também não deveria convidar o menino, porque pode ser um bandido. Ela já está indo longe demais. No primeiro dia deveriam ficar até aí, ficar na festa, depois conversar, conhecer melhor e depois aprofundar as coisas, não logo ir ao ponto. Isso não é coisa que acontece uma vez na vida, essa oportunidade não será uma vez na vida, assim eles deviam ser conscientes, pois podem pegar doenças e ela pode ter uma gravidez precoce, e tenho certeza que se ela ficar grávida ele não vai querer o filho, pois ele gosta do momento, não do que vem depois. Ter filhos é uma responsabilidade que vai ter que carregar para o resto da vida. $\mathrm{O}$ filho não seria um problema quando estão prontos, só vai ser um problema quando eles não estão prontos, pois vão poder querer tirar o filho, ou depois abandoná-lo. Isso sim seria um problema, mas claro que a doença é o principal problema. Eles vão ter muitos problemas futuros, mas o rapaz tem menos consequência, pois a menina pode ficar grávida e o rapaz pode não assumir o filho. A menina pode fazer aborto também, mas quando faz aborto ela que fica prejudicada na sua saúde e pode ser expulsa de casa. O rapaz é só doença e as meninas são mais. Como ela perguntou para o rapaz se ele tinha camisinha, significa que ela se preocupa, que ela tem em mente os riscos, sabe as consequências. Então, eu acho, que como o rapaz não tem, ela não tem e não tem em casa, o que eu acho que ela vai dizer "é melhor não". Ela deveria recusar, e cada um ir para sua casa, ela devia ser responsável, pois se fosse só a gravidez deixaria acontecer, mas tem doenças que são perigosas. Mesmo se ele tivesse prazer, ele deveria estar consciente de que não devia fazer aquilo porque poderia prejudicar a sua saúde. Ele conheceu a menina há algumas horas, não sabe quem realmente é essa pessoa, ela pode ter HIV/SIDA ${ }^{8}$. Então, eles não deveriam fazer o ato sexual quando não conhece a rapariga bem e não se sabe se ela não tem alguma coisa. Se o rapaz não tivesse preservativo não ia fazer, e se ele tentasse pra menina não aceitar.

\section{DSC 1BR - É óbvio que não rolaria}

Se eu fosse o Marcelo e chegasse lá, e não achava camisinha não ia fazer. Vamos deixar para outro dia. Pensa, tu conheceu ela na festa né, não sabe quem ela é, nem sabe o que ela faz. É óbvio que não rolaria, eu pelo menos não, pois não envolveria só uma gravidez, e sim no caso, tipo doenças, e uma que a gente ia curtir uma noite ali, depois a responsabilidade ia ficar com quem? Eu acho que fica a critério da guria, se ela é puta ou não. Se ela é mocinha de casa, decente, ela não vai querer, mas se ela é dessas puta aí.

Os dois discursos apresentados anteriormente trazem a ideia de que os adolescentes não deveriam ter relação sexual, pois não tinham o preservativo. No DSC 1CV o grupo concebe que eles não deveriam ter a relação nem com camisinha, nem sem preservativo. Para eles, a menina não deveria nem ter ido para casa do rapaz, bem como também não deveria convidar

\footnotetext{
${ }^{8}$ Os adolescentes cabo-verdianos fizeram sempre menção a sigla SIDA e não AIDS para se referir a Síndrome da Imunodeficiência Adquirida.
} 
o menino para ir a sua casa. Concebem que eles não deveriam "ir logo ao ponto" e "deviam ser conscientes, pois podem pegar doenças e ela pode ter uma gravidez precoce". No que diz respeito aos adolescentes serem conscientes, a investigação de Benincasa, Rezende e Coniaric (2008) constatou que a totalidade dos adolescentes participantes de seu estudo afirmaram que é comum pensar e agir de forma inconsequente, no entanto, um número pequeno de sujeitos assumiu agir assim. A questão da gravidez e das doenças também emerge no DSC 1BR, mas no discurso cabo-verdiano os adolescentes salientam que o rapaz tem menos consequências que a menina, pois ele pode não assumir o filho.

Outro pensamento comum aos dois discursos é que a decisão seria tomada pela menina, o que podemos evidenciar nos seguintes fragmentos: "ela deveria recusar", "ela devia ser responsável", "se ele tentasse pra menina não aceitar", "fica a critério da guria, se ela é puta ou não". Esses fragmentos revelam que os adolescentes são interpelados pelos discursos produzidos na sociedade. Dessa forma, optamos por abrir um parêntese e pensar tais dados sob a ótica do estudo das relações de gênero o qual "procura compreender as relações entre os gêneros - masculino e feminino - na cultura e na sociedade humanas" (NASCIMENTO, 2015, p. 568).

Entendemos gênero como "a expressão ligada às construções históricas e sociais que definem a diferença sexual em uma cultura" (BOTTON, STREY, ROMANI e YÁSCARA, 2015, p. 601). Tais autoras compreendem que "as ações produzidas por homens e mulheres, como são resultados da cultura em que estamos inseridas(os), acabam produzindo os pensamentos e ações sexistas que a cultura também constrói na sociedade ainda patriarcal em que vivemos" (p. 603). Ao mencionarem que a menina deveria recusar, ser responsável e não aceitar realizar o ato sexual sem preservativo, visualizamos claramente esse pensamento sexista presente nas duas culturas investigadas. É interessante percebermos como esses discursos são potentes, se perpetuam e possuem eco nos adolescentes de hoje.

Santrock (2014, p. 214) evidencia que "a maioria das experiências sexuais adolescentes consiste de os homens tentando avançar sexualmente e ficando a cargo das mulheres estabelecerem os limites dessas investidas sexuais". Wiese e Saldanha (2011, p. 114), em seu estudo, postulam que "ao homem cabe a investida na relação sexual, traçando estratégias para transpor às resistências da parceira, e à mulher ceder ou não". Essas evidências, somadas aos dados de nossa investigação reforçam as marcas sexistas, muito decorrente do patriarcado, conceito que está vinculado "à existência de um discurso que ainda se vale dele como modelo ideológico para o estabelecimento das relações familiares e sociais entre homens e mulheres, modelo que naturaliza e legitima a dominação masculina" (LIMA e SOUZA, 2015, p. 519). 
É importante salientarmos que as relações de gênero "são construídas historicamente, marcadas pela cultura e pelas relações de poder que fundamentam uma hierarquia e uma assimetria social entre homens e mulheres" (NASCIMENTO, 2015, p. 568). Dessa hierarquia, justificam-se pensamentos que deixam a escolha a critério das meninas e, dependendo de sua escolha, irá revelar "se ela é puta ou não". No entanto, Sampaio (2015, p. 168) compreende que "o controle sobre a própria sexualidade, incluindo a saúde sexual e reprodutiva, e a decisão livre, autônoma, sem estar sujeita à qualquer forma de coerção, de discriminação ou de violência, é entendido como direito humano das mulheres". A autora ainda pontua que devemos "discutir e defender os direitos das mulheres de decidirem sobre seu corpo tendo as condições para tomada de decisão de forma livre e autônoma e assim viver sua sexualidade com prazer" (p. 170). Visualizamos nas escolas de educação básica um lugar potente para essas discussões, no entanto, acreditamos que o trabalho realizado nesse espaço deve ir para além do debate das ISTs e da gravidez, contemplando uma reflexão sobre a paternidade, por exemplo, a qual não é debatida nesses espaços.

Apresentamos agora os outros dois discursos, que em sua essência trazem uma ideia diferente dos anteriores:

\title{
DSC 2CV - Quando a temperatura fica quente é difícil controlar
}

\begin{abstract}
No momento as coisas estavam quentes, quando a temperatura fica quente, é difícil de controlar. Nós, adolescentes, queremos fazer uma coisa inesquecível, então fazer sexo com um desconhecido é uma coisa muito frequente pra nossa idade, e como ela já foi para casa do rapaz e não tem camisinha, vai acontecer. É um homem e uma mulher, mas depende da menina, pois pelo rapaz vai acontecer, porque os rapazes sempre querem, mas se a menina não quer o rapaz não faz nada, ele não vai forçar. Mas se o rapaz desistisse, iria ficar muito ruim na ficha e o rapaz gosta de ter filhos. Ele não podia recusar, nem deve, não tem problema se não usar preservativo, pois as tentações falam mais alto. la acontecer principalmente no caso em que a menina convidou, pois quando o rapaz convidou a menina poderia até, suponhamos, que ela seja inocente e acredite que o rapaz não tenha segundas intenções, mas eles não vão pensar nas doenças porque já está no clima, já está quase tudo feito e o filho seria uma benção. Nesse caso, eles deveriam usar outro método que é o coito interrompido.
\end{abstract}


DSC 2BR - Não vai ter o problema de não ter o preservativo

Na hora eles não iam pensar, principalmente se eles tivessem bêbados. É meio que inconsciente, porque o clima já tava quente. Eles vão pensar nas consequências depois de alguns meses, tipo uns nove assim. Tem gente que tem mais consciência, mas acredito que a grande maioria dos jovens hoje em dia não pensa em gravidez na adolescência. E também a gravidez na adolescência virou modinha. Se ela toma anticoncepcional, eu acho que aí que ela ia aceitar, nem que seja uma rapidinha. É uma garantia para ela. Aí ela não ia pensar nas doenças, ela ia pensar só na não gravidez. Ela pensaria assim "ah se eu ficar com ele, eu não vou ter filho" no caso né, não vai ocorrer a gravidez. Só que tipo ela não ia pensar nas DSTs, em pegar uma doença. Na questão da menina acho que ela vai, pois ela não dá bola pra camisinha, já fez o convite. Se ela convidou ele pra casa dela, é porque ela quer alguma coisa. Não vai ter o problema de não ter o preservativo. Essa menina é oferecida, eu acho que ela vai com certeza. Quem vai dizer o sim ou o não é a menina, o menino nunca vai chegar e vai dizer "ah não, não vai acontecer". Se eles estão muito a fim de fazer, eles vão fazer.

Ambos os discursos apresentam que os adolescentes irão sim ter uma relação sexual, mesmo que desprotegida. Destacamos, em alguns trechos, ideias que acabam por culpabilizar a menina: "ia acontecer principalmente no caso em que a menina convidou", "se ela convidou ele pra casa dela, é porque ela quer alguma coisa", "essa menina é oferecida", "quem vai dizer o sim ou o não é a menina". Colocam também que os rapazes sempre querem e que eles nunca vão dizer não. Tal fato foi evidenciado no estudo de Benincasa, Rezende e Coniaric (2008), no qual a totalidade dos sujeitos do gênero masculino afirmaram ser difícil de interromper uma relação pela falta de preservativo.

No DSC 2CV emerge a ideia que os adolescentes querem fazer algo inesquecível, como, por exemplo, transar com um desconhecido. Em relação a isso, Sampaio Filho e colaboradores (2010) evidenciam que para o adolescente vivenciar situações novas e diferentes possibilita o teste dos próprios limites e da experimentação de "emoções inusitadas". Nesse discurso os adolescentes concebem que os envolvidos no dilema "não vão pensar nas doenças" e o filho "seria uma benção". Em relação ao fato de não pensarem nas doenças, as interpretações de Oliveira, Pontes, Gomes e Ribeiro (2009, p. 836) nos parecem interessantes, pois visualizam a adolescência como

um momento em que a individualidade, a personalidade e a noção exata das consequências de seus atos - aliadas ao pensamento mágico e à sensação de invulnerabilidade característicos desta faixa etária - transformam-se em um fundamento favorável para a adoção de práticas não seguras, mesmo com a posse de informação acerca das questões envolvidas nas respectivas decisões.

Os adolescentes cabo-verdianos também apresentam como uma possível saída para o dilema a utilização do método do coito interrompido. Bouzas, Pacheco e Eisenstein (2004) acreditam que tal prática não se configura propriamente como um método de contracepção, mas um comportamento sexual, de pouca eficácia e de grande risco, comum entre adolescentes que estão iniciando sua vida sexual. No estudo de Oliveira e colaboradores

(C) ETD-Educação Temática Digital Campinas, SP $\quad$ v.23 n.1 $\quad$ p. 135-156 jan./mar.2021


(2009) encontra-se a menção de adolescentes ao método do coito interrompido como forma de prevenção de DST e da AIDS. Os autores acreditam que "existe uma lacuna de informação entre os adolescentes acerca das formas de prevenção das doenças sexualmente transmissíveis e dos métodos anticoncepcionais, assim como a existência de crenças que são transmitidas e mantidas pelo seu grupo social" (OLIVEIRA et al, 2009, p. 835).

No discurso "não vai ter o problema de não ter o preservativo" (DSC 2BR) os adolescentes concebem que iria acontecer o ato sexual de uma forma inconsciente. Santrock (2014, p. 209) corrobora com tal ideia ao evidenciar que "em momentos de emoção, como os envolvidos na experimentação sexual, o impulso sexual dos adolescentes pode dominar sua capacidade de tomar decisões competentes". Os adolescentes brasileiros também apontaram que se estivessem bêbados seria um agravante para que o ato fosse concretizado. Em relação a associação do consumo de álcool com o comportamento sexual, Sampaio Filho e colaboradores (2010, p. 511) concebem que:

O adolescente, no plano cognitivo, tem a dificuldade no acesso ao raciocínio formal, a dificuldade em fazer escolhas racionais em longo prazo e a dificuldade em refletir sobre todas as consequências dos seus atos, fazendo com que, muitas vezes, tenha uma percepção distorcida do risco real da infecção pelo HIV nas relações sexuais, pensando que este é um perigo impossível ou altamente improvável. Essa percepção de risco, que já é distorcida normalmente na adolescência, é agravada com o consumo de bebidas alcoólicas.

No DSC 2BR aparece outro pensamento interessante - o de que irá acontecer à relação se a menina estiver tomando anticoncepcional, pois assim seria uma garantia para ela. Diversos estudos evidenciam que quando adolescentes utilizam outra forma de contracepção, acabam por utilizar menos o preservativo nas relações sexuais (VIEIRA et al, 2004; OLIVEIRA et al, 2009). Silva, Miranda e Araújo (2015) ao trabalharem com adolescentes paraenses, perceberam que, muitas vezes, esses acabam se preocupando somente com a prevenção de uma possível gravidez, não levando em conta outros problemas, como por exemplo as ISTs. Vieira e colaboradores (2004) interpretam que isso ocorra pelo fato de que as jovens tendem a se preocupar mais com as consequências imediatas do que com os riscos tardios.

4.2 Análise da moral e ética nos discursos dos adolescentes no que tange à temática das práticas sexuais

Ao buscar nas práticas sexuais explicações no que tange à moralidade dos adolescentes, é possível perceber que no contexto cabo-verdiano existe um dogmatismo em relação a questão da realização do ato sexual entre adolescentes que acabaram de se conhecer. Anterior a decisão sobre a concretização do ato sexual sem o preservativo está o fato impensável de se ter qualquer tipo de relação para além de uma conversa inicial entre

(C) ETD- Educação Temática Digital Campinas, SP $\quad$ v.23 n.1 $\quad$ p. 135-156 jan./mar.2021


os adolescentes, o que não é evidenciado no contexto brasileiro. Os adolescentes caboverdianos acreditam que a situação descrita no dilema moral não é algo

\begin{abstract}
que acontece uma vez na vida, essa oportunidade não será uma vez na vida, assim eles deviam ser conscientes, pois podem pegar doenças e ela pode ter uma gravidez precoce, e tenho certeza que se ela ficar grávida ele não vai querer o filho, pois ele gosta do momento, não do que vem depois. Ter filhos é uma responsabilidade que vai ter que carregar para o resto da vida. O filho não seria um problema quando estão prontos, só vai ser um problema quando eles não estão prontos, pois vão poder querer tirar o filho, ou depois abandoná-lo (DSC 1CV).
\end{abstract}

Com esse trecho do discurso podemos evidenciar duas questões: primeiramente, nota-se que os adolescentes demonstram uma noção de que esse momento não será o único em que poderá realizar o ato sexual. O tudo é agora, ou a ideia de aproveitar o aqui e agora (CORTELLA e LA TAILLE, 2013) parece não imperar nesse pensamento que se mostra extremamente racional, sem imbricamento com os afetos. Nesse caso é possível supor que se trata de um pensamento heterônomo oriundo da coação social, visto que as justificativas para não realizarem o ato sexual não se referem ao desejo do adolescente, mas ao "como deveriam ser", que é dado pelo discurso de regulação social.

Por outro lado, nos discursos DSC 2CV e DSC 2BR outra compreensão é evidenciada, para os adolescentes não haveria como pensar/raciocinar, pois, "o clima já tava quente", iriam pensar nas possíveis consequências depois de algum tempo, não na hora da realização do ato. Nesses dois discursos também parece não existir o imbricamento razão-afeto, acabando por prevalecer o lado afetivo do adolescente que o leva a não conseguir pensar sobre o que está acontecendo. Nota-se, assim, que tanto decisões que tendem mais a racionalidade quanto aquelas que se sustentam mais no afeto produzem práticas de saúde pouco autônomas. Há de se fazer a ressalva de que quando preponderam as razões cognitivas, vindas de discursos heterônomos, á a preservação da saúde, do risco imediato, mas não se pode falar de uma Educação em Saúde, que envolveria a construção de um comportamento autônomo e, por isso, envolvendo, necessariamente, aspectos afetivos.

A outra questão que podemos destacar do fragmento do DSC 1CV relaciona-se a ideia da força de vontade. No momento em que mencionam "gosta do momento, não do que vem depois" e "é uma responsabilidade que vai ter que carregar para o resto da vida" podemos evidenciar que o pensamento está evitando uma consequência futura, que pode gerar problemas, e acaba-se renegando um prazer momentâneo e efêmero (LA TAILLE, 2009). Freitas (2003, p. 96) nos mostra que vai existir vontade quando, "após oscilarmos entre um prazer tentador e um dever, optamos pelo dever". A autora vai mais além postulando que a força de vontade auxilia na superação de um desejo imediato por meio da evocação de valores que não estão presentes em dada situação (seja pela lembrança de situações anteriores, seja pela antecipação de uma situação futura). No DSC 1BR podemos observar um

(C) ETD-Educação Temática Digital Campinas, SP $\quad$ v.23 n.1 $\quad$ p.135-156 jan./mar.2021


questionamento que se alinha ao que estamos discutindo: "É óbvio que não rolaria, eu pelo menos não, pois não envolveria só uma gravidez, e sim no caso, tipo doenças, e uma que a gente ia curtir uma noite ali, depois a responsabilidade ia ficar com quem?". Nesses trechos, claramente os adolescentes realizam uma antecipação do que pode vir a acontecer caso realizem a ação pretendia. Também hierarquizam e assim, acreditam que a possibilidade de se ter um filho ou de adquirir uma IST, pela realização de sexo sem preservativo, não vale a pena e não se configura como a vida que vale a pena ser vivida.

Uma ideia oposta é encontrada no DSC $2 \mathrm{CV}$, no qual os jovens apontam que "as tentações falam mais alto" e que os adolescentes querem "fazer uma coisa inesquecível", como por exemplo praticar sexo desprotegido com um desconhecido. Cortella e La Taille (2013) expõe que para aproveitar o aqui e agora não é necessária força de vontade, e assim o indivíduo acaba por se submeter às vontades. Desse modo, quando emerge no discurso que as tentações prevalecem podemos compreender que o sentimento de força de vontade na verdade configura-se como uma falta de vontade. La Taille (2009, p. 64) irá expor que:

Querer, a todo momento, experimentar satisfações, é se deixar levar pelos acontecimentos, é não antecipar, não hierarquizar, é deixar disposições afetivas momentâneas dirigirem nossa vida. Ora, tal fuga do referido sacrifício, que pode se aplicar a variadas situações de vida, pode se aplicar às relações sociais: queremos que elas sejam imediatamente prazerosas, e desdenhamos aquelas que não o são de imediato, abandonamos aquelas que deixaram de sê-lo.

Freitas (2003) nos mostra que o sistema de valores é que acaba por definir os fins de nossa ação, apontando em quais projetos queremos investir nossas energias. De forma mais clara a autora coloca que:

$\mathrm{O}$ ato de vontade consiste em conservar os valores anteriores e conduzir-se de forma coerente, isto é, não contraditória com esses valores. Em outras palavras, o ato de vontade consiste em descentrar o sujeito da situação atual para permitir um retorno aos valores permanentes de sua escala (FREITAS, 2003, p. 97).

Dessa forma, acreditamos que possuir força de vontade se torna fundamental para realizar o imbricamento entre razão e afetos, pois a vontade "não nos deixa à mercê de desejos e interesses imediatos, permitindo-nos, então, estabelecer fins prioritários a longo prazo e, com base neles, planejar nossas próximas ações" (FREITAS, 2003, p. 98). Assim vislumbramos que seja possível escolhas/decisões mais conscientes sobre sua saúde e consequentemente sobre sua própria vida. 
No contexto brasileiro (DSC 2BR) os adolescentes apontam como fator importante, que corrobora para o sexo sem preservativo, a utilização da pílula contraceptiva oral pela menina. Desse modo, estariam protegidos de uma possível gravidez, o que parece se configurar como sua maior preocupação, sem pensar ou até mesmo sem se preocuparem com as ISTs. Evidenciamos com essa ideia que a gravidez parece aterrorizar mais os adolescentes do que as infecções sexualmente transmissíveis, que é um fator que pode ter uma repercussão mais grave sobre o estado de saúde. Donati e Martins (2015) investigando a conduta sexual de jovens universitárias, constataram que essas se preocupam mais com uma gravidez não planejada do que com uma DST. Os autores relatam que:

\footnotetext{
Quanto à preocupação com as DST, que aparece em segundo plano, elas [as universitárias] justificam que, se estas ocorressem, seriam consequências de um comportamento indesejável e errado, o que revela

uma percepção da DST como uma punição para um comportamento inadequado. Este tipo de raciocínio é característico do pensamento heterônomo, em que o sujeito acredita na justiça imanente, ou seja, crê que todo ato "errado" será inevitavelmente castigado, mesmo que seja por forças divinas ou da natureza (DONATI e MARTINS, 2015, p. 137).
}

O estudo de Gonçalves (2015, p. 190) evidenciou que existe "uma preocupação dos adolescentes em relação à gravidez, por vivenciarem casos de parentes ou conhecidos que tiveram de se casar ou parar de estudar devido à gravidez". Parece-nos que pelo fato da gravidez ter uma consequência mais aparente e material produz um sentimento de exposição de algo visto como errado. Os julgamentos externos pela família e sociedade podem ser mais severos nesses casos. Assim, a regulação da conduta vem do medo de uma repressão externa e do julgamento de uma autoridade heterônoma, sustentando-se em um sentimento de vergonha perante os outros. Pode-se entender também que as infeções sexualmente transmissíveis são passíveis de tratamento, pois projetam-se sobre o futuro. As ISTs tratam sobre algo que não se lida de modo material e imediato como uma gravidez, além de não serem aparentes e vistas socialmente. Pode-se procrastinar o tratamento ou escondê-lo evitando o contato com o sentimento de vergonha. Nota-se então um sentimento heterônomo de referência ao outro como forma de nortear as práticas de saúde.

\section{CONSIDERAÇÕES FINAIS}

Em relação às práticas sexuais, podemos observar que os adolescentes tinham conhecimento sobre os comportamentos saudáveis. No entanto, isso não se configurou como garantia de que esse domínio da informação fosse suficiente para balizar a conduta do sujeito. Acreditamos que isso se deu pelo fato de que "a razão precisa de um rumo, e esse rumo é fornecido pelos investimentos afetivos, pelos valores" (LA TAILLE, 2009, p. 44). Em síntese, para o autor, algo acabará tendo mais valor. Ele vai além, nos mostrando que: 
A cognição permite conceber o mundo. A afetividade tem outro papel: permitir que nos 'apeguemos' ao mundo, que ele, além de ser percebido e concebido, tenha alguma relevância. Nossas competências cognitivas nos possibilitam estruturar o mundo, nossa energia afetiva nos leva a estabelecer prioridades entre seus elementos, ela nos guia entre inúmeras possibilidades de ação. A cognição, disse eu, nos permite conceber o mundo, a afetividade permite nos interessar por ele (LA TAILLE, 2009, p. 38).

Dessa forma, a aposta teórica que utilizamos considera a cognição importante, mas não desconsidera o papel da afetividade, nos permitindo assim compreender de uma forma mais ampla os pensamentos dos adolescentes sobre as possíveis escolhas de saúde, nesse caso as relacionadas as práticas sexuais, que poderão ter que realizar em dado momento de suas vidas.

Após a realização da investigação, podemos postular que não se pode pensar a racionalidade e a afetividade de forma seccionada. Trata-se de dois aspectos da mesma moeda que se interseccionam, se inter-relacionam e que correspondem a dois elementos constituintes de uma conduta única em saúde. Ora, a cognição é fundamental para a compreensão das boas práticas em saúde, mas a afetividade está lá enquanto energética das ações e das escolhas. Pode-se saber o que fazer e querer, mas a intensidade desta vontade (força de vontade) é fundamental e vinculada à afetividade.

O sujeito adolescente tem suas condutas influenciadas pelo pensar e agir moral e os valores que o constituem. No início deste estudo, destacamos que a cognição e a informação são fundamentais para práticas de saúde adequada, todavia, destacamos sua insuficiência. Assim, nos propomos a realizar indicações sobre como a escola e os espaços de educação não formal podem contribuir para promoção de práticas saudáveis junto aos adolescentes. Como Louro (2012, p. 96) evidenciamos que em uma

sociedade que hierarquiza os sujeitos masculinos e femininos, atribuindo-lhes destinos sociais diferentes e desenhando-Ihes perspectivas de vidas desiguais; numa sociedade que assume como legítima apenas uma forma de sexualidade, entendendo a heterossexualidade como a única forma 'normal' e 'natural' de existência, a discussão sobre gênero e sexualidade torna-se urgente e indispensável.

Para isso, quando se busca promover a saúde do sujeito adolescente não podemos pensar apenas em campanhas e ações explicativas que visam elucidar as consequências das ações das más condutas. Com o que evidenciamos neste trabalho, devemos pensar em ações que se voltem para a construção e consolidação de valores positivos sobre si mesmo como uma forma integradora e significativa de cuidado.

Um trabalho com dilemas morais de saúde, podendo ser como o elaborado neste trabalho ou outros que forem mais apropriados, acaba por mobilizar os adolescentes, pois permitem projeção, auxiliam na superação da inibição, promovem diálogo entre pares, 
favorecem o respeito mútuo e uma compreensão mais holística da saúde. Outra alternativa para a questão seria a proposta por La Taille (2009), a qual promove a manifestação e o desabrochar de certos sentimentos morais. Ao transpormos a proposta do autor para as ações de Educação em Saúde, concebemos que ao possibilitar que os adolescentes reflitam sobre o valor humano dos sentimentos morais, como por exemplo simpatia e confiança, poderá ser possível a adoção de condutas de saúde mais imbricadas (razão e afeto) que venham a levar a preservação da vida do sujeito.

Para finalizar, destacamos que os dilemas apresentavam situações que envolviam adolescentes cisgêneros e heterossexuais. No entanto, gostaríamos de mencionar que para avanços na área, estudos similares podem ser desenvolvidos com adolescentes Gays, Lésbicas, Bissexuais, Travestis e Transexuais e com dilemas morais que abordem a forma como vivenciam as práticas e os desejos sexuais, visto que é importante discutir a saúde desses jovens.

\section{REFERÊNCIAS}

BENINCASA, Miria; REZENDE, Manuel. Percepção de fatores de risco e de proteção para acidentes de trânsito entre adolescentes. Bol. psicol, v. 56, n. 125, p. 241-256, dez. 2006.

BENINCASA, Miria; REZENDE, Manuel; CONIARIC, Janaína. Sexo desprotegido e adolescência: fatores de risco e de proteção. Psicol. teor. prat., São Paulo, v. 10, n. 2, p. 121134, dez. 2008.

BOUZAS, Isabel; PACHECO, Andréa; EISENSTEIN, Evelyn. Orientação dos principais contraceptivos durante a adolescência. Adolesc Saude, v. 1, n. 2, p. 27-33, abr./jun. 2004.

BOTTON, Andressa; STREY, Marlene Neves; ROMANI, Patricia Fasolo; YÁSCARA, Arrial Palma. Sexo/Sexismo. In: COLLING, Ana Maria; TEDESCHI, Losandro Antonio (Org.). Dicionário crítico de gênero. Dourados: Ed. UFGD, 2015. p. 601-604.

BRASIL. IBGE. Pesquisa nacional de saúde do escolar: 2015. Rio de Janeiro: IBGE, 2016. Disponível em: https://biblioteca.ibge.gov.br/visualizacao/livros/liv97870.pdf . Acesso em: 10 jul. 2018.

BRÊTAS, José Roberto; MORENO, Rafael; EUGENIO, Daniella; SALA, Danila Cristina; VIEIRA, Thais; BRUNO, Priscila. Os rituais de passagem segundo adolescentes. Acta paul. enferm., São Paulo, v. 21, n. 3, p. 404-411, 2008.

BRÊTAS, José Roberto; OHARA, Conceição; JARDIM, Dulcilene; MUROYA, Renata. Conhecimento sobre DST/AIDS por estudantes adolescentes. Rev. esc. enferm. USP, São Paulo, v. 43, n. 3, p. 551-557, set. 2009. 
CORTELLA, Mario Sergio; LA TAILLE, Yves. Nos labirintos da moral. 10 ed. Campinas: Papirus 7 Mares, 2013.

D'AUREA-TARDELI, Denise. A manifestação da solidariedade em adolescentes: um estudo sobre a personalidade moral. Psicol. cienc. prof., Brasília, v. 28, n. 2, p. 288-303, 2008.

DONATI, Fabiana; MARTINS, Raul. Juventude e conduta sexual: a formação da mulher jovem para a vida sexual. In: MARTINS, Raul; CRUZ, Luciana. Desenvolvimento sócio moral e condutas de risco em adolescentes. Campinas: Mercado de Letras, 2015. p. 117-142.

FREITAS, Lia Beatriz. Autonomia moral na obra de Jean Piaget: a complexidade do conceito e sua importância para a educação, Educ. rev., Curitiba, n. 19, p. 11-22, jan./jun. 2002.

FREITAS, Lia Beatriz. A moral na obra de Jean Piaget: um projeto inacabado. São Paulo: Cortez, 2003.

GATTI, Bernardete. Grupo focal na pesquisa em ciências sociais e humanas. Brasília: Líber Livro, 2005.

GONÇALVES, Maria Augusta. Construção da identidade moral e práticas educativas. Campinas: Papirus, 2015.

KAWASHIMA, Rosana; MARTINS, Raul; BATAGLIA, Patrícia. Histórias e dilemas morais com crianças: instrumento para pesquisadores e educadores. Interfaces da Educ., Paranaíba, v. 6, n. 16, p. 211-230, 2015.

LA TAILLE, Yves de. Moral e ética: dimensões intelectuais e afetivas. Porto Alegre: Artmed, 2006.

LA TAILLE, Yves de. Formação ética: do tédio ao respeito de si. Porto Alegre: Artmed, 2009.

LEFEVRE, Fernando; LEFEVRE, Ana Maria. Discurso do Sujeito Coletivo: um novo enfoque em pesquisa qualitativa (desdobramentos). 2.ed. Caxias do Sul: Educs, 2005.

LEFEVRE, Fernando; LEFEVRE, Ana Maria. Pesquisa de representação social: um enfoque qualiquantitativo: a metodologia do Discurso do Sujeito Coletivo. 2 ed. Brasília: Liber Livro Editora, 2012.

LEFEVRE, Fernando; LEFEVRE, Ana Maria. Discurso do Sujeito Coletivo: representações sociais e intervenções comunicativas. Texto Contexto Enferm., Florianópolis, v. 23, n. 2, p. 502-507, abr./jun. 2014.

LIMA, Lana Lage da Gama; SOUZA, Suellen André de. Patriarcado. In: COLLING, Ana Maria; TEDESCHI, Losandro Antonio (Org.). Dicionário crítico de gênero. Dourados: Ed. UFGD, 2015. p. 515-520.

LOURO, Guacira Lopes. Sexualidade: lições da escola. In: MEYER, Dagmar Elisabeth Estermann; SOARES, Rosângela de Fátima Rodrigues; DALLA ZEN, Maria Isabel Hadckost;

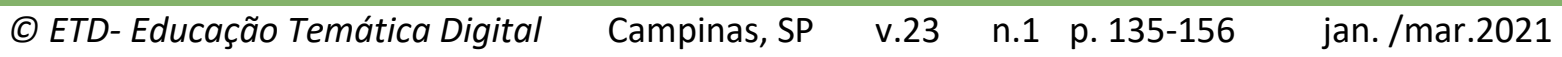


XAVIER, Maria Luisa Merino de Freitas (Org.). Saúde, sexualidade e gênero na educação de jovens. Porto Alegre: Mediação, 2012. p. 93-101.

NASCIMENTO, Alcileide Cabral de. Relações de gênero. In: COLLING, Ana Maria; TEDESCHI, Losandro Antonio (Org.). Dicionário crítico de gênero. Dourados: Ed. UFGD, 2015. p. 565569.

PIAGET, Jean. 0 juízo moral na criança. 4 ed. São Paulo: Summus, 1994.

PUIG, Josep Maria. Ética e valores: métodos para um ensino transversal. São Paulo: Casa do Psicólogo, 1988.

ROMERO, Kelencristina; MEDEIROS, Élide Helena; VITALLE, Maria Sylvia; WEHBA, Jamal. O conhecimento das adolescentes sobre questões relacionadas ao sexo. Rev. Assoc. Med. Bras., São Paulo, v. 53, n. 1, p. 14-19, fev. 2007.

SAMPAIO FILHO, Francisco; SOUSA, Pedro Ricardo; VIEIRA, Neiva; NÓBREGA, Maria de Fátima; GUBERT, Fabiane; PINHEIRO, Patrícia. Percepção de risco de adolescentes escolares na relação consumo de álcool e comportamento sexual. Rev. Gaúcha Enferm., Porto Alegre, v. 31, n. 3, p. 508-514, set. 2010.

SAMPAIO, Paula Faustino. Direitos sexuais e reprodutivos. In: COLLING, Ana Maria; TEDESCHI, Losandro Antonio (Org.). Dicionário crítico de gênero. Dourados: Ed. UFGD, 2015. p. 166-171.

SANTROCK, John S. Adolescência. 14 ed. Porto Alegre: AMGH, 2014.

SILVA, Kelanne; DIAS, Fernanda; MAIA, Carlos; PEREIRA, Dayse Christina; VIEIRA, Neiva; PINHEIRO, Patrícia. A influência das crenças e valores culturais no comportamento sexual dos adolescentes do sexo masculino. Rev. enferm. UERJ, Rio de Janeiro, v. 18, n. 2, p. 247252, abr./jun. 2010.

SILVA, Roberta; MIRANDA, Jaíne; ARAÚJO, Rafaela. Conhecimento de jovens e adolescentes sobre sexualidade: análise em uma escola parceira do PIBID - UFPA. In: X Encontro Nacional de Pesquisa em Educação em Ciências - X ENPEC. Atas... Águas de Lindóia: ABRAPEC, 2015.

OLIVEIRA, Denize; PONTES, Ana Paula; GOMES, Antônio; RIBEIRO, Monique. Conhecimentos e práticas de adolescentes acerca das DST/HIV/AIDS em duas escolas públicas municipais do Rio de Janeiro. Esc. Anna Nery, Rio de Janeiro, v. 13, n. 4, p. 833-841, dez. 2009.

UNICEF. Análise de situação da criança e adolescente em Cabo Verde. Cidade da Praia, Cabo Verde, 2011. Disponível em: <https://www.un.cv/files/crianca2011.pdf>. Acesso em: 09 jul. 2018.

VIEIRA, Maria; GUIMARÃES, Eleuse; BARBOSA, Maria; TURCHI Marília; ALVES, Maria de Fátima; SEIXAS, Mirian; GARCIA, Mônica; MINAMISAVA, Ruth. Fatores associados ao uso de preservativo em adolescentes do gênero feminino no município de Goiânia. DST - J bras Doenças Sex Transm., v. 16, n. 3, p. 77-83, 2004.

(C) ETD-Educação Temática Digital Campinas, SP $\quad$ v.23 n.1 $\quad$ p.135-156 jan./mar.2021


WIESE, Iria; SALDANHA, Ana. Vulnerabilidade dos adolescentes às DST/AIDS: ainda uma questão de gênero?. Psic., Saúde \& Doenças, Lisboa, v. 12, n. 1, p. 105-118, 2011.

\section{AGRADECIMENTO}

À Coordenação de Aperfeiçoamento de Pessoal de Nível Superior (CAPES) pela concessão da bolsa para realização do doutorado sanduíche na Universidade de Cabo Verde (UniCV), por meio do Programa Pró-Mobilidade Internacional da Associação de Universidades de Língua Portuguesa (AULP), a qual possibilitou a produção de dados em Cabo Verde.

\section{Revisão gramatical realizada por:}

Isabela Camargos Ribeiro

E-mail: icribeiro.portugues@gmail.com 